\title{
Santiago de Compostela entre o mito e a realidade en Trece badaladas/Trece campanadas
}

\author{
JAVIER RIVERO GRANDOSO \\ Universidad Complutense de Madrid \\ javierriverograndoso@ filol.ucm.es \\ Recibido: abril 2013. Aceptado: mayo 2013
}

Resumo: Santiago de Compostela tivo sempre unha especial relevancia nas artes pola súa función de cidade-templo. Axiña foi mitificada e creada literariamente como un espazo sagrado pola presenza da Catedral e do sepulcro do Apóstolo Santiago. Porén, queremos comprobar se esta visión permanece vixente no século XXI, e para iso escollemos a novela Trece badaladas de Suso de Toro, pois a adaptación do argumento ao cinema na película Trece campanadas, dirixida por Xavier Villaverde, permítenos examinar en dúas disciplinas artísticas a visión da cidade.

O noso obxectivo é analizar como funciona a cidade e os procesos de mitificación e desmitificación que se perseguen tanto na novela como na película para descubrir os propósitos dos autores.

Palabras chave: literatura e cine, cidade nas artes, Suso de Toro, Xavier Villaverde, Trece badaladas.

\begin{abstract}
Santiago de Compostela has always had a special relevance in art because of its function as a city-temple. It was soon mythified and created literarily as a sacred space for the presence of the cathedral and the grave of Apostle Santiago. However, we intend to analyze if this vision still remains in the $21^{\text {st }}$ century. In order to check it, we have chosen Suso de Toro's novel Trece badaladas, and its fim adaptation Trece campanadas, directed by Xavier Villaverde, because these works allow us to examine the vision of urban space in two artistic disciplines.
\end{abstract}

Our aim is to analyze the city and the processes of mythification and demythification that are intended in the novel as well as in the film to discover the purposes of the authors.

Keywords: literature and cinema, city in the arts, Suso de Toro, Xavier Villaverde, Trece badaladas. 
Santiago de Compostela é unha cidade que dende a época medieval aparece nos escritos literarios. O carácter de cidade-tumba co sepulcro do Apóstolo Santiago, segundo a lenda na que «un eremita, llamado Pelayo, vio unas luminarias sobre aquel lugar y lo puso en conocimiento de Teodomiro, obispo de la diócesis de Iria Flavia, quien encontró el mausoleo del apóstol» (Etayo Gordejuela 2011: 136), fixo que axiña xurdise unha literatura claramente mitificadora. O mesmo Etayo Gordejuela fai un repaso dos textos que preparaban esta inventio nos séculos anteriores, como a Carta del obispo León de Jerusalén, o Brevario de los Apóstoles, ou o Comentario del Apocalipsis de Beato de Liébana.

A popularización do Camiño de Santiago axiña converte a cidade nun centro de culto e peregrinación que perdura até a actualidade, o que produciu que Santiago de Compostela fose «punto de encuentro de las corrientes de vanguardia, a lo largo de los siglos y en todos los dominios de la cultura y del pensamiento, sedimentadas, todas ellas, en la ciudad actual» (Mejía Ruiz 2011: 195-196).

O noso obxectivo é estudar se perdura ou non, e de que maneira, a imaxe mitificada da cidade de Santiago de Compostela na actualidade. No século XX apareceu un importante número de obras de diversos xéneros que trataban de xeito moi diferente a recreación literaria da cidade. Podemos poñer como exemplo a novela criminal, tratada por autores como Carlos G. Reigosa, Suso de Toro ou Diego Ameixeiras, na que o carácter mítico da cidade compostelá desaparece ou, polo menos, é rebaixado en favor dos crimes, dos problemas actuais que ten Santiago de Compostela, como outras cidades modernas. Para facer o estudo sobre a mitificación e a desmitificación da cidade, escollemos unha novela e unha película: Trece badaladas, de Suso de Toro, e a adaptación do argumento ao cinema Trece campanadas, dirixida por Xavier Villaverde.

Para comezar, debemos facer fincapé na anormalidade do proxecto de adaptación da novela á pantalla do cinema ${ }^{1}$. Xeralmente

las novelas llevadas al cine suelen serlo después de su publicación, cuando el número de ejemplares vendidos (o el prestigioso aval de ciertas recomendaciones críticas) ha convertido sus títulos en relativamente memorables (González Herrán 2004: 27)

coa conseguinte publicidade que pode ofrecerlle o éxito do libro, que posibilita que sexan espectadores potenciais os lectores da obra literaria. Porén, non foi así neste caso, xa que a idea orixinal de Suso de Toro era rodar unha serie de trece capítulos. De feito, o autor escribiu o argumento e redactou algunhas escenas do guión, mais para o autor foi imposíbel atopar uns produtores dispostos a levar o seu proxecto á televisión. Despois de falar con Pancho Casal e Xavier Villaverde, deciden aproveitar o potencial do argumento para filmar unha

1 Para profundar no proceso de creación simultánea das dúas obras e no análise xeral da novela e a película, recomendamos ao lector os seguintes traballos: González Herrán (2004) e Rivero Grandoso (2012). 
película. Suso de Toro tenta reconverter o seu guión de serie para o esquema dunha película, mais o resultado é moi longo, dunha duración aproximada de cinco horas. Entón, o autor e o director Villaverde inician a redacción do guión xuntos, e pouco tempo despois sumaranse Curro Royo e Juan Vicente Pozuelo. No entanto, o rumbo do proxecto afástase cada vez máis da idea orixinal do escritor, quen decide volver ao traballo solitario ao que está acostumado para resucitar, esta vez en forma de novela, o seu primeiro argumento.

Deste xeito, xorden, da mesma idea, a novela e a película, moi diferentes entre si por un proceso de adaptación anómalo, xa que o que se adapta é o argumento e non a novela. Non estamos a falar, pois, dunha adaptación convencional. No entanto, as dúas creacións teñen éxito, porque por Trece badaladas Suso de Toro consegue o Premio Nacional de Narrativa de 2003, algo que en lingua galega só lograran antes Alfredo Conde e Manuel Rivas; e Trece campanadas obtén o Premio Mestre Mateo de 2003 á mellor película.

A novela céntrase principalmente no mito fáustico, no pauto co demo, xa que o protagonista é controlado por un ser malvado que guía os seus pasos para conseguir o que esa persoa quere. Ese ser escuro é recoñecido como o titor -que é o sobrenome co que coñecen o Mestre Mateo-que dende as sombras controla a vida de Xacobe para lograr cumprir co seu desexo, relacionado coa tumba do Apóstolo na Catedral. Outros dous personaxes teñen tamén un papel destacado na obra: Celia, a muller que se namora de Xacobe e tenta evitar que caia no mal, e o Confrade Ramírez, un vello moi relixioso que, como un detective moi singular, vixía a Xacobe, debido a que cre que a participación deste na Confraría ten uns propósitos malintencionados.

Por contra, para a película, os guionistas preferiron centrar a problemática do personaxe protagonista na relación entre pai e fillo. «El giro en el mito que manejábamos era evidente. Habíamos virado de Fausto (el pacto con el mal) a Hamlet (la lucha con el fantasma paterno)» (Royo y Pozuelo 2003: 138). Deste xeito, Mateo é un famoso escultor que é asasinado aparentemente pola súa muller diante do seu fillo, Xacobe, apenas un rapaz. Anos despois, Xacobe volve a Santiago de Compostela, mais o fantasma do seu pai, que quere que remate a súa obra para ter un sitio na Catedral, persegue e atormenta o protagonista.

A mudanza temática esténdese tamén á consideración xenérica da obra, debido ao «enfoque radicalmente distinto en cuanto a la propia concepción de los conflictos narrados: mágico (o sagrado) en De Toro, psicológico (o psicopatológico) en Villaverde» (González Herrán 2004: 28). Por tanto, o resultado das dúas obras variou considerabelmente da súa idea orixinal e deu lugar a unhas notábeis diferenzas entre si.

Despois destas breves liñas que explican as principais variacións entre a novela e a película, imos centrar a nosa atención no desenvolvemento do medio urbano nas dúas creacións que, ben que o autor francés Baby o inclúe xunto ao tempo nas unidades de situación — na súa clasificación das funcións narrativas-, nós o aplicaremos soamente ao espazo, para abordar, 
como explica Baby, os elementos que «décrivent généralement le décor, le milieu ou l'ambiance physique, l'entourage, l'endroit, la place, la position, etc.» (Baby 1980: 19)2.

Na obra de Suso de Toro o espazo urbano ten unha especial relevancia, até o punto de ser o xermolo da historia, xa que o autor tenta trasladar unha serie que daban pola televisión cando el era un neno, El fantasma del Louvre, á súa cidade: «Digamos que a cidade me suxeriu unha parte do argumento. A cidade segregou practicamente o argumento. A miña idea da cidade como un labirinto que se fai arredor dun centro que é unha tumba. E de ese labirinto saíronme presenzas fantasmais» (González Herrán e Tarrío Varela 2002: 238). A identificación da cidade cun labirinto aparece na propia novela, cando Celia, a guionista que presenta o seu proxecto a Xacobe, lle fala do nacemento do seu traballo: «Suxeriumo a cidade propia, este labirinto de ruelas de pedra, coma se fose o labirinto do Minotauro...» (De Toro 2002: 154). Obviamente, pode apreciarse unha certa correspondencia entre Celia e o mesmo Suso de Toro: sen dúbida, o autor traslada á súa personaxe a inspiración do seu traballo, e ademais é citado o director da película, Xavier Villaverde, como posíbel director da serie que propón Celia, nunha clara intertextualidade coa película que se estaba a facer ao mesmo tempo.

Primeiro escribín unha guía da cidade e iso levoume a estudiala e vela con outros ollos, vina cos ollos do estranxeiro, iso axuda a coñecela. [...] a idea de que nalgunhas ocasións a Berenguela tanxe trece veces e se crea unha hora especial, propicia para que o demo faga das súas. Se xuntas iso coa propia cidade, tan labiríntica e chea de recunchos... digamos que xa tes a semente dunha historia de misterio. (De Toro 2002: 88-89)

Aínda que non poidamos deternos nisto, convén destacar, como algúns críticos sinalaron (González Herrán 2004: 28-29), a función de alter ego que ten o personaxe de Celia e as posibilidades de estudo que ofrece como tema metaliterario, xa que Celia funciona como pretexto para reflexionar sobre o feito literario e o proceso creativo.

A película tamén asume a concepción da cidade como un lugar labiríntico, un espazo de perda para o protagonista, xa que pola noite, na Praza de Quintana, e fronte á Catedral, o persegue o fantasma do seu pai. A ambientación que ofrece Santiago de Compostela resulta moi adecuada para un thriller coma este: pouca luz, rúas estreitas, chan mollado... Un tebroso labirinto en que o protagonista tenta fuxir do seu pai, baixo as miradas das inquietantes esculturas a e banda sonora que prepara o espectador para unha escena tensa: o protagonista corre polas rúas en obras e chega até un mercado - ben que non está preto da Catedral, a maxia da ficción do cinema permite esta licenza- en que as portas, dúas reixas unidas, están pechadas. Xacobe non pode fuxir e ten que se enfrontar ao seu pai, que lle pide que remate a súa obra escultórica.

2 Un bo traballo teórico sobre a adaptación do espazo literario ao espazo fílmico é o de Becerra (2002). 
De feito, a cidade exerce un estraño poder sobre o protagonista, que mesmo confesa que «es esta ciudad, me está volviendo loco» (Royo, Pozuelo y Villaverde 2003: 86). O carácter labiríntico da cidade faise explícito nas palabras de Mateo, que mostra a mesma concepción coa que Suso de Toro comezou o proxecto:

MATEO. (Sonríe.) Estoy muerto...

MATEO pasa por delante del fotomontaje del pórtico.

MATEO. ...como tantas cosas en esta ciudad. ¿Te has dado cuenta? Santiago es un inmenso cementerio, un laberinto de piedra construido alrededor de una tumba... (sonríe.) ... y allí vamos a poner nuestra escultura. (Royo, Pozuelo y Villaverde 2003: 58)

Como parte do proceso mitificador de Compostela, o centro é a tumba do Apóstolo Santiago, e o resto da cidade só ten valor en tanto que lle rende tributo á Catedral, xa que está subxugado á relevancia relixiosa, cultural e económica do templo. A intención de Mateo, como xa indicamos, é conseguir que o seu fillo remate o grupo escultórico para que a súa obra permaneza na Catedral, e así conseguir a ansiada eternidade. Por tanto, a película continúa nunha liña mitificadora, pois o valor da obra de Mateo depende de se consigue permanecer na Catedral, e o templo ten unha función canonizadora.

O achegamento de Suso de Toro á cidade de Santiago de Compostela está feito dende unha óptica que busca a verosimilitude. Por iso, nas páxinas da novela atopamos unha cidade críbel, unha urbe rodeada por un halo de misterio, mais tamén é a capital de Galiza, un dos núcleos de peregrinación máis importantes de Occidente e conta cunha das universidades máis antigas de España. Así pois, Santiago de Compostela é cidade administrativa, turística e universitaria, e todo isto aparece dalgún xeito amalgamado na Praza do Obradoiro, como apunta acertadamente Gómez-Montero:

En la Plaza del Obradoiro, convertida en metáfora de la ciudad, conviven hoy día Catedral, Concello y Universidad —a su vez emblemas de los agentes institucionales generadores de los discursos urbanos (si acaso hoy más que nunca en simbólica compañía del Hostal, emblema del uso y potencial turístico de la ciudad)—, pero numerosos aspectos de la historia civil de la ciudad parecen no encontrar cabida en ese entramado, de forma semejante a como esa plaza no dio cabida al nuevo agente institucional que desde hace treinta años ha generado la quizá mayor transformación en su historia (me refiero a la sede administrativa de la Xunta de Galicia en los antiguos cuarteles extramuros, en el edificio San Caetano). (2012: 43-44)

Como cidade universitaria e turística aparece na obra Trece badaladas, cando o confrade, personaxe moi relixioso, reaccionario e de pensamento ultraconservador —homófobo, misóxino, contrario aos cambios da vida moderna-, se 
queixa da marcha dos seus veciños e da xente coñecida, que son substituídos polos principais «clientes» da Santiago actual:

na parte antiga da cidade eu era xa como unha reliquia doutro tempo, foron morrendo case todos os meus veciños, ou marcharon vivir ás casas do alfoz con fillos que os coidasen. As casas están baleiras, deshabitadas e noutras, os meus veciños eran estudiantes de pensión. Cada día sentíame un pouco máis fóra de alí e como expulsado do meu mundo, o meu Santiago morreu. (De Toro 2002: 41)

nesta cidade nosa está a darse unha revolución silenciosa e xa nada é como era, todo vai sendo arrombado pola forza do turismo e da estudantina. Un ás veces sente que estamos a ser expulsados por unha man invisible dos nosos sitiais. Claro que Santiago sempre foi así, sempre viviu da xente que viña de fóra. (De Toro 2002: 71-72)

Tampouco lle gusta ao confrade o Entroido, unhas festas excesivamente inmorais para unha persoa coma el, e demanda a participación da Confraría para protestar ao Concello polos excesos execrábeis que supoñen encontros como o que ten na rúa do Vilar, onde ve a tres rapaces novos disfrazados de noiva, peregrino e sacerdote, en actitudes pouco decorosas (De Toro 2002: 105-106).

Na película vemos tamén as festas da mocidade polo Entroido, que coincide cun primeiro momento de desorientación de Xacobe, que percibe como o fantasma do seu pai o está posuíndo. A festa das máscaras, do disfrace, na que todo o mundo xoga a ser outra persoa, aparece nun instante de crise para o protagonista, no que non sabe ben se segue sendo el mesmo ou se Mateo está comezando a controlar a súa mente e o seu corpo. Este aspecto é criticado por algún estudoso, xa que «o filme non contribúe para a creación dunha nova perspectiva, Santiago seguirá, polo momento, vinculada cinematograficamente aos tópicos da vida estudantil» (López López 2003: 73).

Na novela, o confrade critica a conversión de Santiago de Compostela nun espazo para os turistas que buscan o seu recordo nas tendas de suvenires, ás que critica por facer negocio co sepulcro do Apóstolo Santiago. Esta visión da cidade é a percepción do que algúns críticos chamaron «disneylandización» ${ }^{3}$, é dicir, a adaptación da cidade non tanto para as necesidades dos seus habitantes como para os turistas que deben atopar a imaxe de postal que esperaban antes da súa viaxe. O espazo urbano vai perdendo paulatinamente as súas funcións vitais para comezar a ser un escaparate agradábel á vista dos visitantes. Muñoz Carrobles estuda esta reconversión que sufriu a cidade compostelá:

Santiago de Compostela se ha convertido, con el paso de los años, en el parque temático del Apóstol, hecho que genera pingües beneficios a las arcas

3 Parécenos necesario lembrar que, segundo Baudrillard, «Disneylandia es un modelo perfecto de todos los órdenes de simulacros entremezclados» (2008: 29). Por tanto, resulta acertado o concepto para referirnos ao proceso que ocorre nas distintas cidades que van perdendo a súa identidade para adaptarse ás expectativas do turista. 
municipales y autonómicas, así como a los comerciantes y hosteleros de la ciudad. Lo que algunos autores han dado en llamar «disneylandización» de la ciudad encuentra un buen ejemplo en Compostela, donde la catedral y especialmente la fachada de la Plaza del Obradoiro cumple la función de castillo de Blancanieves, su icono inconfundible, el logotipo de la «ciudad-marca». Lo religioso y lo espiritual que históricamente habían rodeado a la ciudad queda ahora desmitificado, las indulgencias se compran y se venden en las tiendas de souvenirs y los nuevos «inquilinos» de la ciudad pululan como hormigas por las calles. (Muñoz Carrobles 2011: 211)

Celia, nunha das poucas cuestións que coincide co confrade, tamén sente tristeza pola acumulación do turismo que fai perder á cidade a súa tranquilidade e o seu carácter sombrío: «E de feito a cidade ten moito de sombrío. Agora xa non; con tanto turista e tanto estudante isto é un revoltallo, unha lástima. Todo xente de paso» (De Toro 2002: 91).

En efecto, Santiago de Compostela, unha cidade de cerca de 100000 habitantes, ten os mesmos problemas de calquera cidade moderna. Deste xeito, xunto á espectacularidade e a magnificencia da Catedral, os veciños teñen que convivir coas molestias da urbe actual, como demostra este fragmento no que Celia tenta aparcar e exalta os aspectos positivos da parte vella:

Conducía dentro dun video-clip melancólico de tons grises entre un tráfico brutal por vías violentas. Aquel era o lado da cidade que máis odiaba, sabía o necesario, era o tráfico do traballo, das mercadorías, mais ela amaba o ritmo pausado que podía ter vivindo na parte vella. Os tumultos de turistas e das noites de movida non lle chegaban no seu ático desde o que vía tellados e nubes. Ela sabía que en certa medida fuxía da súa época, que aquel fragor de tráfico era a verdade da cidade e do tempo [ ] Viu unha praza de aparcamento na rúa e apurouse a ocupar o sitio, aparcar era un problema. (De Toro 2002: 52-53)

Por tanto, os elementos desmitificadores son evidentes na novela: os estudantes que se divirten pola noite de festa en festa, os numerosos turistas que buscan a súa foto xunto á Catedral e que enchen os locais de suvenires, e o tránsito e os problemas de aparcamento que lembran aos habitantes as dificultades da cidade moderna. Santiago non é, pois, soamente esa cidade mítica en que descansan os restos do Apóstolo, senón que tamén garda un lado moito menos interesante para a súa explotación económica.

A parte nova da cidade, que é practicamente excluída na película, aparece tamén na novela como se fose un labirinto, ao igual que a zona vella, mais sen o encanto e a beleza desta: «Ela guindara xa había un pedazo o paraguas, volto do revés e inservíbel polo vento furioso, e avanzara primeiro polas rúas do Ensanche da cidade, rúas agoniantes que formaban un novo labirinto sen centro, un eco remoto da cidade antiga, baixo un vendaval de chuvia, e logo entrara nas lousas do labirinto da parte vella» (De Toro 2002: 319). Con certeza, a zona nova contrasta co casco histórico, con lugares pouco agradábeis como, segundo o confrade, a Praza de Galicia, cara a onde camiña coa presenza da habitual chuvia santiaguesa: 
[...] fun baixo a chuvia cara á zona nova, é un fervedoiro insoportábel de ruído, autos e xente polo día, que envolto no escuro da noite disimula a súa fealdade. A noite fai que vexamos menos o que hai e así a nosa imaxinación traballa, unhas veces para ben e outras para mal. Naquel caso aquela inhóspita praza de Galicia case parecía romántica, por así dicir. (De Toro 2002: 198)

As modernidades son rexeitadas xeralmente polo confrade, nada acostumado á cidade actual. Por iso, cando ten que deixar o seu auto nun aparcadoiro subterráneo, sente que ese lugar ten «algo de baixada aos infernos que me desagrada» (De Toro 202: 101). O medo que lle ten Ramírez aos aparcadoiros simboliza a súa incapacidade de adaptarse aos novos tempos, e perpetúa a súa idea baseada na lenda de que o Mal está na cidade e se manifesta coas trece badaladas, como cando morreu o seu irmán Rafael, que era o campaneiro e reloxeiro da Berenguela.

Deste xeito, a zona nova da cidade, que non goza da aura mítica que si garda a vella, aparece como a fea e incómoda prolongación do centro urbano, sen o encanto e o interese que teñen as rúas que se atopaban intramuros. Polo tanto, a zona nova é a constatación de que Santiago é unha cidade moderna, e que, como tal, ten os espazos e os problemas propios dunha cidade do século XXI.

A película, en troques, aproveita outros espazos que non reciben moita atención na novela. É o caso do Museo de Arte Contemporánea de Santiago de Compostela, lugar onde traballa Claudia, a amante de Mateo e quen propón a Xacobe que remate a obra do seu pai. Nese edificio atópase unha exposición das esculturas de Mateo, e alí comeza a discusión que terá con Xacobe, posuído este polo fantasma do seu pai, que rematará nunha persecución até unha igrexa, onde Claudia caerá dende o alto dunha estada. O moderno edificio contrasta cos inmóbeis do casco histórico e presenta deste modo a zona nova. Porén, e aínda que o museo non teña o aspecto lúgubre propicio para a escena de medo, é tamén aproveitado, como os arredores da Catedral, para un episodio tenso no que esta vez é Xacobe o perseguidor, e que remata coa morte de Claudia. Polo tanto, o espazo está a mercé do xénero da película e da vontade de producir inquietude no espectador.

Dous espazos relevantes na xeografía compostelá teñen tamén un papel destacado na novela: o parque da Alameda e a Cidade da Cultura. O famoso parque da Alameda é a antítese do labirinto da cidade: «Naquela cidade tan labiríntica e claustrofóbica aquel lugar permitía respirar o aire do espazo aberto, había terra mais tamén había ceo» (De Toro 2002: 113). O parque é protagonista en dous momentos da novela: cando Xacobe e Celia dan unha volta e falan sentados nun banco xunto a estatua de Valle Inclán e cando Xacobe se reúne co mestre Mateo no paseo da Ferradura, episodio importante porque supón o definitivo sometemento do protagonista. Este último episodio modifica, ou polo menos atenúa, o signo positivo do parque, o gran espazo aberto da cidade, xa que se ve enturbado por unha escena inquietante. Como apunta López López ao referirse ao papel que desempeñan estes espazos urbanos, «non son só puntos espaciais de referencia, senón que xogan protagonismo, sen eles a trama non tería razón de ser» (2003: 72). 
Por outra banda, a Cidade da Cultura é claramente criticada polos personaxes cando aínda as obras de construción só estaban a comezar, quen denuncian o seu carácter innecesario e artificial no monte Gaiás. Neste caso, trátase dun diálogo entre Celia e Xacobe, e é a muller a que fai fincapé na vacuidade do novo complexo arquitectónico:

- [...] A substancia da cidade é a memoria histórica.

-Pois agora estase actualizando coa Cidade da Cultura que están a construír...

—Unha cidade baleira. É a máis grande estupidez... ou canallada. Suplantar unha cidade real por unha virtual, unha cousa viva por unha imaxe. (De Toro 2002: 90)

A mesma opinión que ten tamén o confrade, quen sinala a corrupción como motivo da súa construción e afonda na artificialidade dun proxecto que pretende ser un simulacro da cidade:

Agora anda asociado coa construtora da familia dun conselleiro, xa coñeces como vai todo iso, tamén anda a familia do alcalde de certa cidade, xa sabes, e está metido na construción da Cidade da Cultura, que non se sabe moi ben para que é, para o turismo, claro. A cidade da cultura xa é Santiago. (De Toro 2002: 293)

A construción da Cidade da Cultura é criticada pola súa pretensión de ser simulacro da cidade real. $\mathrm{O}$ proxecto arquitectónico orixinal pretendía copiar o esquema urbano de Santiago de Compostela, e por iso xorden as preguntas dos personaxes sobre a idoneidade da construción, pois son conscientes da artificialidade dunhas obras que van destinadas a ser un parque temático que semelle a verdadeira cidade. As ideas expresadas por Baudrillard sobre o hiperreal e a precesión dos simulacros poden aplicarse perfectamente a este caso, xa que a Cidade da Cultura é un simulacro da zona vella de Santiago, mais, por suposto, sen historia e sen habitantes: unha especie de parque temático dedicado á cultura, a pesar de que a arte e a evolución a través dos séculos permanecen no casco histórico da cidade.

Volvendo á zona vella, o centro dese labirinto que alí se forma, como se referiu en múltiples ocasións Suso de Toro, está ocupado pola Catedral. O templo é tamén lugar central tanto na novela como na película: é o espazo onde o antagonista quere entrar a través do protagonista. Se na novela o Mestre Mateo quere que os restos do seu fillo ocupen o sepulcro do Apóstolo, na película o escultor Mateo pretende que o seu fillo remate a súa obra para que subsista por sempre na Catedral.

A tumba eríxese así na cifra simbólica de Compostela, na expresión metafórica do subsconsciente urbano, cuxa polivalencia é capaz de resumir tanto a vivencia de Celia (para ela trátase dunha cidade misteriosa) como a de Xacobe para quen Santiago non é máis ca unha pequena e asfixiante cidade. Ademais, a metáfora 
da tumba - ao aludir ao sepulcro do Apóstolo—é tamén portadora da linguaxe identitaria de Compostela polo que sintetiza igualmente o estatuto simbólico definidor culturalmente do espazo urbano. (Gómez Montero 2007: 26)

Alí vai Mateo tras fracasar no seu intento para que Xacobe lle permitise lograr o seu obxectivo, e alí quedan as súas cinzas. Nas dúas obras, ficar na Catedral e o fin que persegue o fantasma: na novela, deixar o corpo do seu fillo; na película, situar alí o grupo escultórico. A Catedral é, deste xeito, mitificada, o espazo onde os personaxes poden perdurar para sempre. Conquistar o templo é conquistar a cidade e a eternidade.

No entanto, a curia catedralicia non permitiu que se rodaran escenas na Catedral, a pesar de que no guión non aparecía ningún aspecto que puidese resultar ofensivo. Por iso, tiveron que facer un decorado que imitase a Catedral, especialmente para o campanario da Berenguela, onde se desenvolve a escena final, o clímax da película. Desta reconstrución e do valor da Catedral na película falan o escenógrafo e o ambientador: «La película se aproxima al terror psicológico. Por tanto, la Catedral, una obra barroca que enmascara y en gran parte destruyó la antigua construcción románica, constituye un decorado metafórico del terrorífico drama, que en este caso no puede calificarse de "gótico"» (Rosell y Subirachs 2003: 147). Nesa escena Xacobe tenta fuxir do seu pai e sube até a campá Berenguela, seguido por Mateo. Alí enriba ameaza o fantasma do seu pai con tirarse ao chan e rematar xa o pesadelo no que está a tornar a súa vida, mais xusto cando está a piques de facelo, chegan María e o psiquiatra e conseguen falar con Xacobe: dinlle que as visións de Mateo son produto dun trauma da súa infancia porque en realidade foi el quen disparou e matou o seu pai para protexer a súa nai. A décimo terceira badalada fora á da unha da madrugada, mais o impacto do suceso producira que Xacobe esquecese todo o que ocorrera nesa hora.

Suso de Toro escolle para o final da súa obra unha igrexa moito máis pequena e tranquila, un templo no que fose factíbel que tivese lugar o diálogo entre o mestre Mateo e Celia. É a igrexa de San Fiz de Solovio, que dende o principio sabemos, a través do confrade, que está pechada por obras de restauración. Suso de Toro elixe este espazo para dotar de verosimilitude a súa narración, xa que resultaría incríbel que esa conversa final que manteñen os dous personaxes puidese ocorrer na Catedral, sempre chea de xente, xa sexan fieis ou turistas. Ademais, San Fiz de Solovio é a primeira igrexa construída na cidade, polo que achega o valor da volta á orixe que terá ese episodio.

Nos dous finais impera a visión mítica de Santiago de Compostela: se na película é a Catedral, coa súa grandeza, o espazo escollido para desenvolver o clímax con Xacobe e o seu pai nas alturas, na novela é tamén un templo onde ten cabida un suceso máxico, posíbel nunha cidade con esa aura de misterio.

Por tanto, e para ir rematando, podemos concluír que Santiago de Compostela é un elemento moi importante na construción destas dúas obras, ben que na novela Suso de Toro aproveita toda a cidade e na película só aparece a zona vella, que ten un especial protagonismo nas escenas que buscan unha maior tensión no espectador. O espazo urbano desempeña unha función fundamental, 
até o punto de motivar as accións que levan a cabo os personaxes. A inclusión na novela de toda a cidade e de distintas voces posibilita que se ofreza ao lector distintas visións do entorno urbano, e por iso, fronte ao idealizado casco histórico, aparecen a normalidade das rúas novas - tan correntes como as rúas de calquera cidade, sen ningún encanto particular-e as incomodidades da turística parte antiga, chea de viaxeiros e tendas de recordos polo día e de estudantes e bares pola noite. Por esta razón, mentres que na película non hai elementos desmitificadores, si que aparecen na novela, aínda que permanezan algúns tópicos dispostos para agrandar a lenda en torno a Santiago de Compostela. Tamén a presenza demoníaca do Mestre Mateo supón mostrar a cara oculta da cidade, como sinala Acuña (2010: 80-81), aínda que este lado non mostrado da urbe poida ir en consonancia a aumentar o carácter misterioso, e, por tanto, mítico, de Santiago de Compostela.

O interese da cidade en Suso de Toro resulta obvio, xa que, ademais, foi a semente da súa obra e pretende, dalgunha maneira, sentar un precedente con ela:

En este novela intenté hacer un argumento de Compostela, un argumento en el que enhebre los mitos, que englobe el sentido y la fuerza del lugar; los mitos telúricos, los mitos cristianos, y después sobre eso traté de amalgamar las leyendas y la historia. Estoy convencido de que ésta va a ser la novela de Santiago de Compostela, la que le va a dar el argumento. Deseo que a partir de esta novela Santiago sea interpretada a la luz de su argumento. (Rodríguez 2003: 8)

As dúas obras, polo tanto, tratan a aura mítica de Santiago, xa que, como di Celia, «Santiago é mito, todo o que escribas sobre a cidade é literatura. Só podes escribir se te tiras a fondo por ese camiño, pola literatura que nace do mito» (De Toro 2002: 94).

\section{BIBLIOGRAFÍA}

Acuña, A. (2010) «Santiago de Compostela: encuentro de transeúntes» [en línea], Angulo Recto. Revista de estudios sobre la ciudad como espacio plural, vol. 2, núm. 2, pp. 69-81. En: http://www.ucm.es/info/angulo/volumen/ Volumen02-2/varia02.htm.

Baby, F. (1980) «Du littéraire au cinématographique: une problématique de l'adaptation», Études littéraires, vol. 13, n. ${ }^{\circ} 1$, pp. 11-41.

Baudrillard, J. (2008) Cultura y simulacro, Barcelona, Editorial Kairós.

Becerra, C. (2002) «Aproximación ao estudio do espacio; o espacio literario e o espacio fílmico», Boletín Galego de Literatura, 27, pp. 25-38.

Etayo Gordejuela, M. (2011) «La representación artística de la ciudad de Santiago. Leyendas y escrituras» [en línea], Ángulo Recto. Revista de estudios sobre la ciudad como espacio plural, vol. 3, núm. 1, pp. 135-173. En: http:// www.ucm.es/info/angulo/volumen/Volumen03-1/varia04.htm. http://dx.doi. org/10.5209/rev_ANRE.2011.v3.n1.195. 
Gómez-Montero, J. (2007) «Urbs mythica - Cidade submisa - Futura polis: Pautas de lectura de Compostela na narrativa de Suso de Toro», Anuario Grial de Estudos Literarios Galegos, pp. 24-39.

- (2012) «Del mito a la anamnesis. Subconsciente urbano y la memoria histórica en Trece badaladas y Home sen nome de Suso de Toro (con un apunte sobre la dificultad de la reconstruccion memorialstica en Sete palabras)», en Sadi Lakhdari (coord.), Voces de Galicia. Manuel Rivas et Suso de Toro, París, Indigo \& côté femmes, pp. 42-66.

González Herrán, J. M. (2004) «Dos árboles de una misma semilla: Trece badaladas, de Suso de Toro / Trece campanadas, de Xavier Villaverde», Ínsula, 688, abril 2004, pp. 27-29.

González Herrán, J. M., e Tarrío Varela, A. (2002) «Encontro en Compostela con Xabier Villaverde e Suso de Toro», Boletín Galego de Literatura, 27, pp. 237-261.

López López, I. (2003) «Trece Badaladas: falseando as pedras de Compostela baixo a chuvia», Madrygal: Revista de Estudios Gallegos, 6, pp. 69-73.

Mejía Ruiz, C. (2011) «Viajar a la ciudad del Milagro», en Eugenia Popeanga (coord.), Ciudades mito: modelos urbanos culturales en la literatura de viajes y en la ficción, Berna, Peter Lang, pp. 193-206.

Muñoz Carrobles, D. (2011) «Desmontando Santiago de Compostela: la desmitificación de una ciudad», en Eugenia Popeanga (coord.), Ciudades mito: modelos urbanos culturales en la literatura de viajes y en la ficción, Berna, Peter Lang, pp. 207-225.

Rivero Grandoso, J. (2012) «De Trece badaladas a Trece campanadas, ou de como dun argumento xurdiron unha novela e unha película (I)», Madrygal: Revista de Estudios Gallegos, 15, pp. 131-138.

Rodríguez, L. (2003) ««He escrito la novela de mi ciudad». Entrevista a Suso de Toro», Lateral, 103-104 (xullo-agosto), pp. 8-9.

Rosell, J. + Subirachs, R. (2003) «La ambientación en Trece campanadas», en Curro Royo, Juan Vicente Pozuelo y Xavier Villaverde, Trece campanadas: Guión cinematográfico, Madrid, Ocho y Medio, pp. 147-148.

Royo, C. + Pozuelo, J. V. + Villaverde, X. (2003) Trece campanadas: Guión cinematográfico, Madrid, Ocho y Medio.

Toro, S. de (2002) Trece badaladas, Vigo, Xerais. 